\title{
Pityriasis lichenoides et varioliformis acuta after influenza vaccine*
}

\author{
Breno Augusto Campos de Castro ${ }^{1}$ \\ Renata Leal Bregunci Meyer ${ }^{1}$ \\ Moises Salgado Pedrosa ${ }^{1}$
}

\author{
Juliana Milagres Macedo Pereira ${ }^{1}$ \\ Fernanda Marques Trindade ${ }^{1}$ \\ André Costa Cruz Piancastelli ${ }^{1}$
}

DOI: http:/ / dx.doi.org/10.1590/abd1806-4841.20153492

\begin{abstract}
A bstract: The etiology of pityriasis lichenoides is unknown. One of the accepted theories admits that PL is an inflammatory response to extrinsic antigens such as infectious agents, drugs and vaccines. In recent medical literature, only the MMR vaccine (Measles, Mumps and Rubella) was associated with the occurrence of this disease. We present a case of a male, 12 year old healthy patient who, five days after Influenza vaccination, developed erythematous papules on the trunk, abdomen and limbs, some with adherent crusts and associated systemic symptoms. This case report is notable for describing the first case of pityriasis lichenoides et varioliformis acuta associated with the vaccine against Influenza.
\end{abstract}

Keywords: Child; Influenza vaccines; Pityriasis lichenoides; Tetracycline

\section{INTRODUCTION}

Pityriasis lichenoides (PL) represents a group of inflammatory cutaneous diseases with variable clinical spectrum. Mucha was the first one to separate the acute form of PL from the chronic form of this disease in 1916. Later, in 1966, Degos et al described an ulceronecrotic variant of acute PL associated with fever, which was named Febrile Ulceronecrotic MuchaHabermann disease. ${ }^{1}$ Currently three subtypes of this spectral disease are recognized: pityriasis lichenoides et varioliformis acuta (PLEVA), pityriasis lichenoides chronica (PLC) and febrile ulceronecrotic MuchaHabermann disease. ${ }^{1,2}$

It is known that PL affects children and young adults, peaking in the third decade of life. ${ }^{1}$ Men are three times more affected than women, whereas PLC is six times more common than PLEVA. ${ }^{3,4}$
PLEVA is clinically presented as erythematous macules smaller than $5 \mathrm{~mm}$, which rapidly evolve to papules with thin micaceous desquamation. Papules with a vesicopustular central point, eventually hemorrhagic adherent crust and varioliform scars are not uncommon. Residual hypochromias and hyperchromias may occur, rarely accompanied by malaise, fever, lymphadenopathies and arthritis. In PLC papules usually are asymptomatic with an indolent course of weeks to months, leaving residual hyperchromic macules. On the other hand, in febrile ulceronecrotic Mucha-Habermann disease, there is rapid progression to necrotic papules with hemorrhagic blisters, confluent ulcers and pustules. Systemic manifestations are common. ${ }^{1,2,5}$

Received on 14.06.2014.

Approved by the Advisory Board and accepted for publication on 19.08.2014.

Work performed at Hospital da Polícia Militar de Minas Gerais - Belo Horizonte (MG), Brazil.

Financial Support: None.

Conflicts of Interest: None.

1 Hospital da Polícia Militar de Minas Gerais - Belo Horizonte (MG), Brazil.

(C)2015 by Anais Brasileiros de Dermatologia 


\section{CASE REPORT}

Male patient, 12 years old, without previous history of chickenpox. Five days after vaccination against the Influenza virus, he presented multiple erythematous papules on the trunk, abdomen and limbs, associated with mild pruritus. Initially with no systemic symptoms, the patient was diagnosed at a basic health service facility as having chickenpox and medication was prescribed to control symptoms. With no improvement of cutaneous symptoms, the patient was treated at the emergency care facility with fever $\left(38.4^{\circ} \mathrm{C}\right)$, tachycardia, moderate dehydration, vomiting and prostration.

At the dermatological examination he presented $2-4 \mathrm{~mm}$ erythematous papules, some finely scaly, located on limbs, trunk and abdomen. Many were purpuric, with necrotic adhered crusts and associated varioliform scars (Figures 1, 2 and 3). Complementary examinations showed the presence of leukocytosis $\left(16,770 \mathrm{~mm}^{3}\right)$ and C-reactive protein $(37.5 \mathrm{mg} / \mathrm{l})$. Serologies for Hepatitis B and C, Epstein Barr virus, Cytomegalovirus, Rubella and Toxoplasmosis were negative. Histopathological examination revealed an extensive lymphocytic inflammatory infiltrate invading the epidermis, with vacuolization of basal layer, associated with extravasated erythrocytes (Figures 4 and 5). The diagnosis of PLEVA was established from the association of clinical and histopathological data.

The patient was hospitalized and prednisone $1 \mathrm{mg} / \mathrm{kg} /$ day was prescribed for 10 days, erythromycin $50 \mathrm{mg} / \mathrm{kg} /$ day twice a day for 7 days. He remained in observation for two days due to the associated systemic symptoms. Later, it was decided to replace macrolide with tetracycline $1 \mathrm{~g} /$ day for 28 days, due to persistence of cutaneous lesions. After three months, the patient obtained an almost complete remission of lesions. Phototherapy was not indicated since there was improvement of symptoms.

\section{DISAUSSON}

Although PLC is the most common variant in the population in general, recent studies have demonstrated that the PLEVA is the most common presentation form in children. ${ }^{3}$ In most cases the etiology remains unknown.

There are three accepted theories to explain the pathogenesis of PL. ${ }^{1}$ The first states that it would be an inflammatory reaction triggered by extrinsic antigens, such as: infectious agents (HIV, cytomegalovirus, Epstein-Barr virus, parvovirus B19, Toxoplasma gondii, Mycoplasma virus and Staphylococcus); drugs (hormone therapy with estrogen-progesterone, chemotherapeutics); and vaccine (MMR - mumps, measles and rubella). 6,7 The second hypothesis

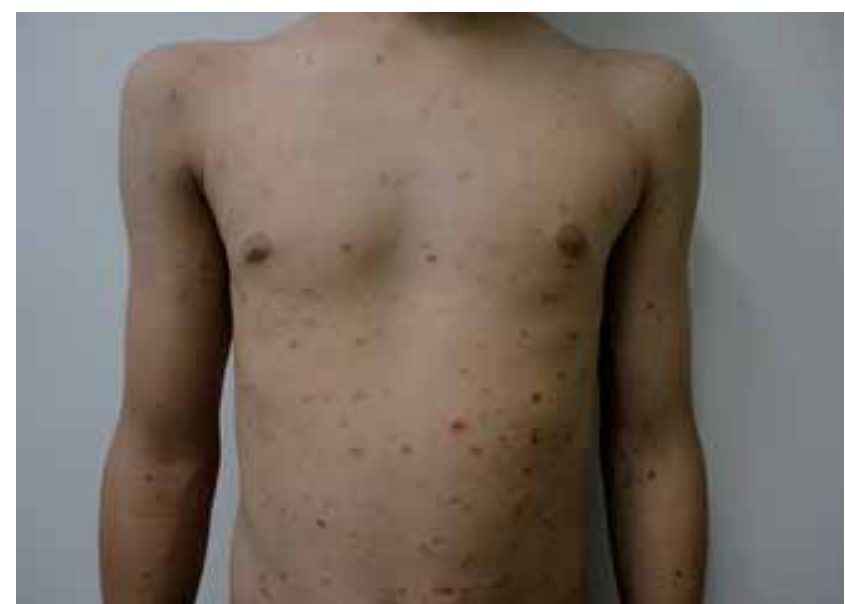

FIGURE 1: Multiple erythematous papules, some with adhered crusts, on trunk and abdomen

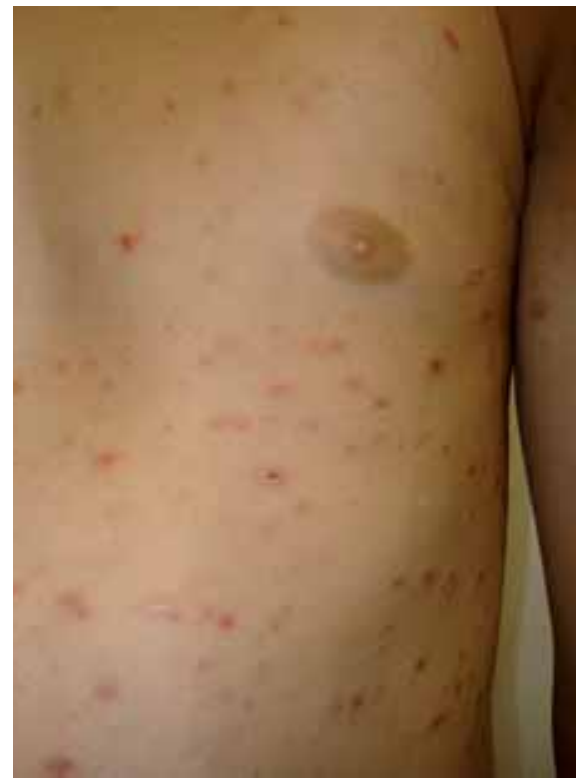

\section{Figure 2:}

At a higher magnification, papules with varioliform scars associated with brownish erythematous macules

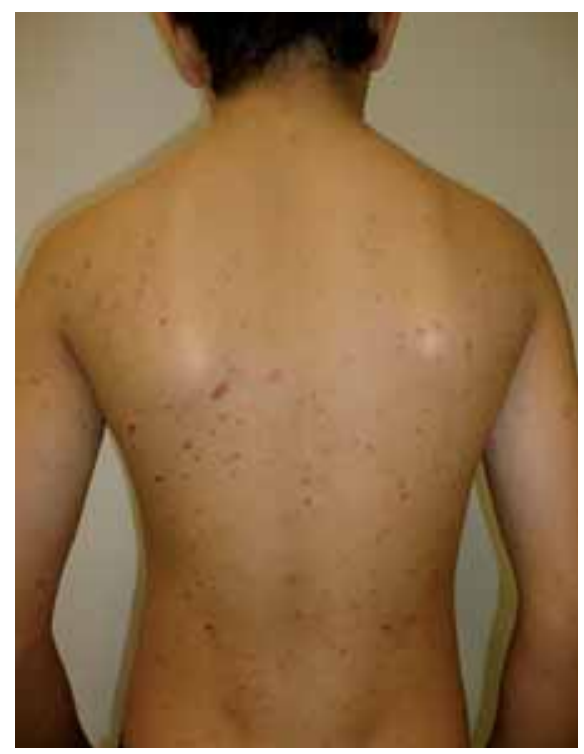

\section{FIGURE 3:}

Fine scaly purpuric papules on the back 


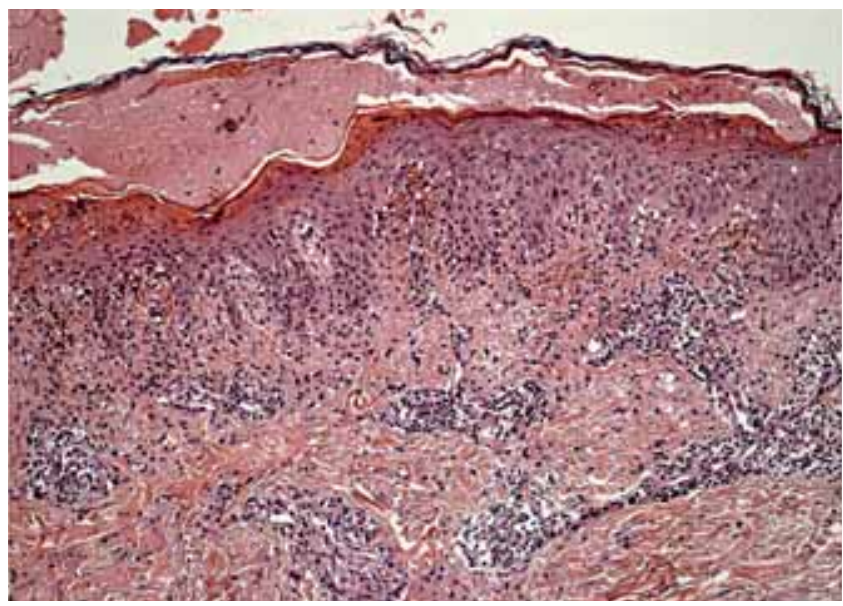

FIgURE 4: Extensive inflammatory lymphocytic infiltrate invading the epidermis, parakeratosis and spongiosis

(HE, 50x)

describes its lymphoproliferative origin. Some authors demonstrated the loss of mature antigen T cells CD2, CD3 and CD5 in PL, besides clonal proliferation of $\mathrm{T}$ cells in $50 \%$ of PLEVA cases (association with Hodgkin's lymphoma and lymphomatoid papulosis). ${ }^{1}$ Finally, some authors demonstrated the presence of a component of immunocomplex-mediated vasculitis. ${ }^{1}$

The diagnosis is established clinically and by histopathology, which varies according to the phase, acute or chronic. The most common changes include: lymphocytic infiltrate with mixed neutrophils and histiocytes, exocytosis, parakeratosis, red blood cell extravasation and necrosis of keratinocytes with intraepidermal vesicles. ${ }^{1}$ In immunohistochemistry the presence of CD30+ lymphoid cells and atypical lymphoid cells may occur in an unspecific way, but suggest the diagnosis of lymphomatoid papulosis, an important differential diagnosis of PL. ${ }^{1}$ The differential diagnosis of chickenpox also stands out, an extremely prevalent disease, which is usually mistaken for PLEVA.

This report becomes interesting by allowing to infer the probable cause of development of PLEVA. As reported, the patient showed first symptoms five days after taking the vaccine against Influenza, composed of different strains of M yxovirus influenzae virus.

In recent medical literature, associations between Influenza vaccine and dermatological diseases are described as palmoplantar keratoderma, lichen planus, Gianotti-Crosti syndrome, erythema

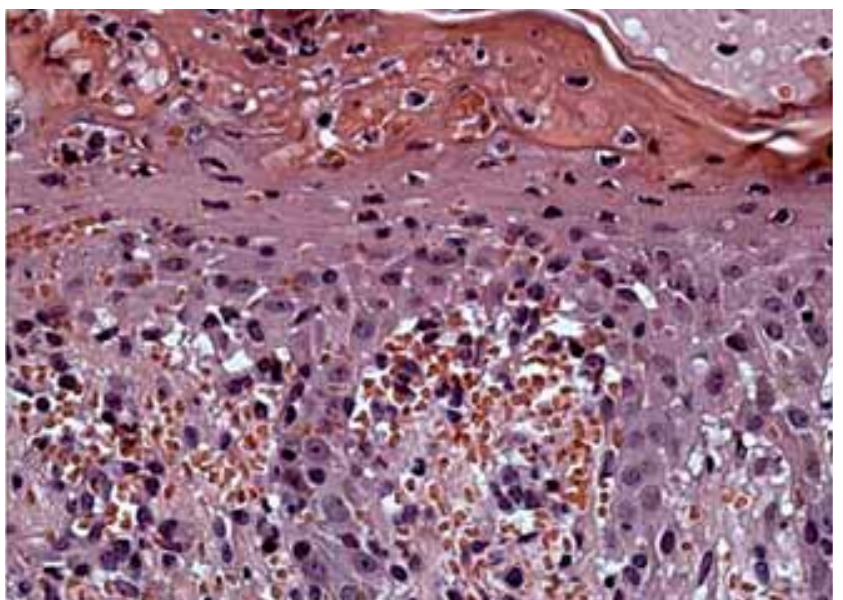

FIgURE 5: Detail of red blood cells extravasation and vacuolization of basal layer (HE, 100x)

multiforme and pityriasis rosea. ${ }^{5,8}$ However, after extensive review of scientific literature (PubMed, Science Direct, Scielo and Lilacs), we did not find reports of association between PLEVA and this vaccine. Only two cases of PL induction by vaccination stand out, both MMR (mumps, measles and rubella) cases. ${ }^{5,6}$ The systemic presentation of PLEVA is also rare. Symptoms like fever, adynamia, vomiting and dehydration are uncommon, being found more frequently in the ulceronecrotic variant of PL.

First-line therapy include the use of topical corticoids and calcineurin inhibitors. Several authors report success using tetracycline in the dose of $1-2 \mathrm{~g} /$ day (for patients over 8 years of age) and erythromycin, $1-2 \mathrm{~g} /$ day, for two to four weeks. ${ }^{1}$ However, some studies demonstrate that children present lower therapeutic response to the use of antibiotics than adults. Wahie et al. ${ }^{9}$ reported a response rate of only $25 \%$ in children using erythromycin, while in adults there was preferences for minocycline with a response rate of $75 \% .^{7}$ UVB phototherapy has proved more efficient than antibiotics in children, but with high rates of recurrence. ${ }^{7}$ As second-line therapy methotrexate, PUVA, dapsone, cyclosporine, prednisone and retinoids stand out. ${ }^{1,10}$

We emphasize the necessity of in-depth instruction of medical professionals regarding the recognition of pityriasis lichenoides. It is frequently mistaken for chickenpox, especially when it involves the pediatric age bracket and manifests itself with polymorphic lesions. $\square$ 


\section{REFERENCES}

1. Bowers S, Warshaw EM. Pityriasis lichenoides and its subtypes. J Am Acad Dermatol. 2006;55:557-72.

2. Khachemoune A, Blyumin ML. Ptyriasis lichenoides: pathophysiology,classification, and treatment. Am J Clin Dermatol. 2007;8:29-36.

3. Romaní J, Puig L, Fernández-Figueras MT, de Moragas JM. Pityriasis lichenoides in children: Clinicopathologic review of 22 patients. Pediatr Dermatol. 1998;15:1-6.

4. Gelmetti C, Rigoni C, Alessi E, Ermacora E, Berti E, Caputo R. Pityriasis lichenoides in children: A long-term follow-up of eighty-nine cases. J Am Acad Dermatol. 1990;23:473-8.

5. Sato NA, Kano Y, Shiohara T. Lichen planus occurring after influenza vaccination: report of three cases and review of the literature. Dermatology. 2010;221:296-9.

6. Gil-Bistes D, Kluger N, Bessis D, Guillot B, Raison-Peyron N. Pityriasis lichenoides chronic after measles-mumps-rubella vaccination. J Dermatol. 2012;39:492-3.

7. Gunatheesan S, Ferguson J, Moosa Y. Pityriasis lichenoides et varioliformis acuta: a rare association with the measles, mumps and rubella vaccine. Australas $\mathrm{J}$ Dermatol. 2012;53:e76-8.

8. Lim D, Rademaker M, Gardner D, Oakley A. Palmoplantar keratoderma: an adverse reaction to influenza vaccination. Australas J Dermatol. 2011;52:298-300.

9. Wahie S, Hiscutt E, Natarajan S, Taylor A. Pityriasis lichenoides: the differences between children and adults. Br J Dermatol. 2007;157:941-5.

10. Khachemoune A, Blyumin ML. Pityriasis lichenoides. Pathophysiology, classification, and treatment. Am J Clin Dermatol. 2007:8:29-36.

\author{
M AILING ADDRESS: \\ Breno A ugusto Campos de Castro \\ A venida do Contorno, 2787 \\ Bairro Santa Efigênia \\ 30110-017 - Belo H orizonte - M G \\ Brazil \\ E-mail: dermatobreno@yahoo.com.br
}

How to cite this article: Castro BAC, Pereira JMM, Meyer RLB, Trindade FM, Pedrosa MS, Piancastelli ACC. Pityriasis lichenoides et varioliformis acute after influenza vaccine. An Bras Dermatol. 2015;90(3 Supl 1):S181-4. 